\title{
Percutaneous minimally invasive versus open spine surgery in the treatment of fractures of the thoracolumbar junction: a comparative effectiveness review
}

Authors Giuseppe MV Barbagalloํ․ Emily Yoder², Joseph R Dettori², Vincenzo Albanese ${ }^{1}$

Institutions ${ }^{1}$ Department of Neurosciences, Division of Neurosurgery, Policlinico University Hospital,

Catania, Italy

${ }^{2}$ Spectrum Research Inc, Tacoma, WA, USA

\section{ABSTRACT}

Study design: Comparative effectiveness review.

Objective: To determine the comparative effectiveness and safety of percutaneous minimally invasive versus open spine surgery for fractures of the thoracolumbar junction.

Methods: A systematic review of the English-language literature was undertaken for articles published between 1970 and March 15, 2012. Reference lists of key articles were also systematically checked. We attempted to identify all articles that reported on the effectiveness and/or safety comparing minimally invasive surgery (MIS) with open surgery for thoracolumbar fractures in the adult population. Articles containing hematological or neoplastic fractures primarily were excluded. Other exclusions included reviews, editorials, case series, non-English-language written studies, and animal studies. We rated the overall body of evidence using a modified Grades of Recommendation Assessment, Development and Evaluation (GRADE) system for diagnostic and therapeutic studies.

Results:

- Two studies (Level of Evidence III) met our inclusion criteria.

- Radiographic outcomes were similar between treatment groups.

- Postoperative incisional pain was less in patients undergoing percutaneous MIS.

- Patient function as assessed by the Hannover Spine Score, the SF-36 and the MacNab criteria were slightly higher in the percutaneous minimally invasive group, but not statistically significant.

- Percutaneous MIS resulted in less blood loss and shorter length of hospital stay than open surgery.

- No complications were reported using percutaneous MIS.

Conclusion: Limited data suggest that percutaneous techniques are associated with less postoperative pain, less blood loss, a shorter hospital stay, and a slightly better functional outcome. However, concerns remain on the effectiveness of percutaneous techniques in correcting spinal deformity and achieving bony fusion. Further studies are needed to verify these preliminary findings. 


\section{STUDY RATIONALE AND CONTEXT}

Thoracolumbar fractures are the most common spinal fractures, with an incidence ranging between 18 and 30 cases per 100,000 inhabitants/year [1,2]. Patients requiring surgical treatment usually undergo either open surgery, including pedicle screw fixations or thoracoscopic approaches. Recently, percutaneous pedicle screw fixation techniques have gained popularity as minimally invasive procedures able to provide spinal stability with a lower rate of morbidity.

\section{KEY QUESTIONS}

With respect to fractures of the thoracolumbar junction:

- What is the comparative effectiveness of percutaneous minimally invasive versus open spine surgery?

- What is the comparative safety of percutaneous minimally invasive versus open spine surgery?

\section{MATERIALS AND METHODS}

Study design: Comparative effectiveness review.

Search: PubMed, Cochrane Collaboration Database, and bibliographies of key articles.

Dates searched: 1970 through March 15, 2012.

Inclusion criteria: (1) Skeletally mature men and women (>18 years); (2) traumatic fractures of the thoracolumbar junction; treatment comparing minimally invasive and open surgery.

Exclusion criteria: (1) $\geq 50 \%$ of population included non-traumatic fractures (hematological or neoplastic); (2) vertebroplasty/kyphoplasty as the only surgical intervention; (3) non-surgical treatment as the comparator.

Analysis: Descriptive.

Overall strength of evidence: For evaluating the risk of bias in individual diagnostic studies, we rated the level of evidence using the rating scheme developed by the Oxford Centre for Evidence-based Medicine and used with modification by The Journal of Bone and Joint Surgery American Volume. A more detailed description is in the Web Appendix at www.aospine.org/ebsj. After individual article evaluation, the overall body of evidence with respect to each key question was determined based on modified precepts outlined by the Grades of Recommendation Assessment, Development and Evaluation (GRADE) system.

Fig 1 Results of literature search.

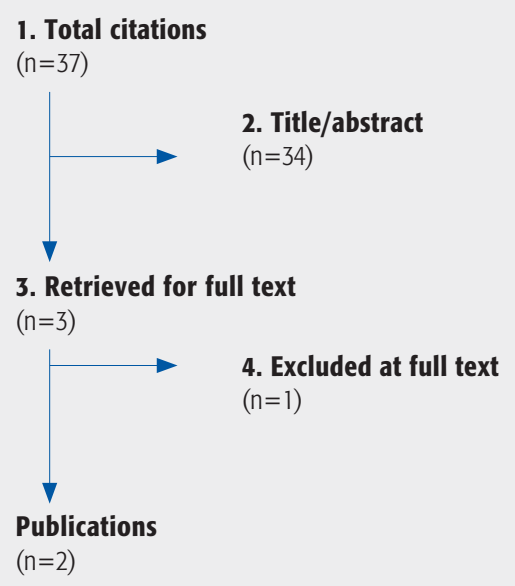




\section{RESULTS}

- From 37 citations, 3 underwent full-text review; 2 met our inclusion criteria and are summarized in this review (Fig 1). Both were retrospective cohort studies (LoE III). See the Web Appendix for critical appraisal.

- One study compared percutaneous minimally invasive surgery (MIS) with open surgery in 38 patients $(35 \%$ type $\mathrm{Al} ; 24 \%$, A2; and $41 \%$, A3) with a 1 -year mean follow-up (Table 1) [3]. The second study treated 23 patients, all with type A fracture [4].

\section{Comparative effectiveness of percutaneous MIS (Table 2)}

- Radiographic outcomes (mean change from preoperative to postoperative follow-up) of sagittal Cobb angle, fractured vertebral body angle, anterior vertebral body height, posterior vertebral body height, and bisegmental wedge angle were similar between treatment groups in one or both studies.

- Postoperative incisional pain was less in patients undergoing percutaneous MIS ( 1.5 versus 2.2 , VAS, $P<.05$ ) in one study [3]. However, $2.0 \mathrm{~cm}$ improvement for pain has been recommended by some as the minimal clinically important difference [3]. Patient function as

Table 1 Characteristics of included studies.

\begin{tabular}{|c|c|c|c|c|c|}
\hline Study (y) & Study design & Population & Diagnosis & Treatment & Follow-up \\
\hline $\begin{array}{l}\text { Wang et al } \\
\text { [5] (2010) }\end{array}$ & $\begin{array}{l}\text { Retrospective } \\
\text { cohort study }\end{array}$ & $\begin{array}{l}\mathrm{N}=38 \\
\text { Minimally invasive surgery } \\
\text { (MIS; Sextant percutaneous } \\
\text { pedicle screw fixation) } \\
\mathrm{n}=17 \\
\text { Mean age: } 41.6 \text { (range, } \\
28-54 \text { ) y } \\
\text { Male: } 76.5 \% \\
\text { Open surgery (open pedicle } \\
\text { screw fixation) } \\
\mathrm{n}=21 \\
\text { Mean age: } 45.0 \text { (range, } \\
\text { 37-61) y } \\
\text { Male: } 85.7 \%\end{array}$ & $\begin{array}{l}\text { MIS (Sextant percutaneous pedicle screw fixation) } \\
\text { Mechanism of injury } \\
\text { - Falling: } 41.2 \% \text { ( } 7 / 17 \text { patients) } \\
\text { - Traffic injuries: } 41.2 \% \text { (7/17 patients) } \\
\text { - Tumble: 17.6\% (3/17 patients) } \\
\text { AO fracture classification } \\
\text { - A1: } 35.3 \% \text { (6/17 patients) } \\
\text { - A2: } 23.5 \% \text { (4/17 patients) } \\
\text { - A3: } 41.2 \% \text { ( } 7 / 17 \text { patients) } \\
\text { ASIA score } \\
\text { - Incomplete injury (grade D): } 29.4 \% \text { ( } 5 / 17 \text { patients) } \\
\text { - Neurologically intact (grade E): } 70.6 \% \text { ( } 12 / 17 \text { patients) } \\
\text { Open surgery (open pedicle screw fixation) } \\
\text { Mechanism of injury } \\
\text { - Falling: } 71.4 \% \text { (15/21 patients) } \\
\text { - Traffic injuries: } 9.5 \% \text { ( } 2 / 21 \text { patients) } \\
\text { - Tumble: } 14.3 \% \text { ( } 3 / 21 \text { patients) } \\
\text { - Strike by dropping heavy object: } 4.8 \% \text { (1/21 patient) } \\
\text { AO fracture classification } \\
\text { - A1: } 52.4 \% \text { (11/21 patients) } \\
\text { - A2: } 42.9 \% \text { ( } 9 / 21 \text { patients) } \\
\text { - A3: } 4.8 \% \text { ( } 1 / 21 \text { patients) } \\
\text { ASIA score } \\
\text { - Incomplete injury (grade D): } 57.1 \% \text { (12/21 patients) } \\
\text { - Neurologically intact (grade E): } 42.9 \% \text { ( } 9 / 21 \text { patients) }\end{array}$ & $\begin{array}{l}\text { MIS } \\
\text { (Sextant percutaneous } \\
\text { pedicle screw fixation) } \\
\text { Injury segments } \\
\text { - T12: } 17.6 \% \\
\text { (3/17 patients) } \\
\text { - L1: } 58.8 \% \\
\text { (10/17 patients) } \\
\text { - L2: } 23.5 \% \\
\text { (4/17 patients) } \\
\\
\text { Open surgery } \\
\text { (open pedicle } \\
\text { screw fixation) } \\
\text { Injury segments } \\
\text { - T12: } 33.3 \% \\
\text { (7/21 patients) } \\
\text { - L1: } 28.6 \% \\
\text { (6/21 patients) } \\
\text { - L2: } 38.1 \% \\
\text { (8/21 patients) }\end{array}$ & $\begin{array}{l}\text { Mean f/u: } 11.6 \\
\text { (range, 8-24) mo } \\
100 \% \mathrm{f} / \mathrm{u}\end{array}$ \\
\hline $\begin{array}{l}\text { Wild et al } \\
\text { [4] (2006) }\end{array}$ & $\begin{array}{l}\text { Retrospective } \\
\text { cohort study }\end{array}$ & $\begin{array}{l}\mathrm{N}=23 \\
\text { MIS (percutaneous pedicle } \\
\text { fixation) } \\
\mathrm{n}=10 \\
\text { Mean age: } 49.1 \mathrm{y}^{*} \\
\text { Male: } 90 \% \%^{*} \\
\text { Open surgery } \\
\text { (conventionally open } \\
\text { posterior surgery with } \\
\text { pedicle fixation) } \\
\mathrm{n}=11 \\
\text { Mean age: } 33.5 \mathrm{y}^{*} \\
\text { Male: } 63.6 \% *\end{array}$ & $\begin{array}{l}\text { AO fracture classification: } \\
-100 \%(21 / 21) \text { type A fracture }\end{array}$ & $\begin{array}{l}\text { Both groups used } \\
\text { Synthes universal } \\
\text { spine system's fixateur } \\
\text { interne }\end{array}$ & $\begin{array}{l}\text { Mean f/u: } 25.5 \\
\text { and } 67.9 \text { mo for } \\
\text { both groups } \\
91.3 \% \mathrm{f} / \mathrm{u}\end{array}$ \\
\hline
\end{tabular}

* After loss to follow-up (f/u). 
assessed by the Hannover Spine Score, the SF-36, and the MacNab criteria were slightly higher in the percutaneous minimally invasive group although they did not reach statistical significance.

- The overall strength of evidence for radiographic and postoperative outcomes is insufficient due to the literature shortage on this topic and imprecision of results (Table 4).

\section{Comparative safety of percutaneous MIS (Table 3)}

- Percutaneous MIS was consistently better than open surgery with respect to surgical blood loss, postoperative blood loss, surgical time, and length of hospital stay.
- Wild et al [4] reported that no incorrect screw positioning, infections, or neurological symptoms occurred in either treatment group. In the open treatment of Wang et al [5], three pedicle screws were malpositioned (no symptoms or revision); two patients had incision stagger (successful re-stitching); and one patient developed deep vein thrombosis (managed successfully with drug therapy). There were no complications reported in the percutaneous MIS group.

- The overall strength of evidence for evaluating the safety of percutaneous minimally invasive versus open spine surgery for thoracolumbar fractures is low because of the low quality of the literature (Table 4).

\section{CLINICAL GUIDELINES}

- None found.

Table 3 Comparative safety between percutaneous minimally invasive and open surgery for thoracolumbar fracture.

invasive and open surgery for thoracolumbar fracture.

\begin{tabular}{|c|c|c|c|}
\hline Outcome & $\begin{array}{l}\text { Minimally } \\
\text { invasive }\end{array}$ & Open & $\boldsymbol{P}$ \\
\hline Radiographic & Mean change & Mean change & \\
\hline \multicolumn{4}{|c|}{ Sagittal Cobb angle, ${ }^{\circ}$} \\
\hline - Wang et al [5] & $10.3 \pm 6.1$ & $9.3 \pm 7.3$ & .651 \\
\hline \multicolumn{4}{|c|}{ Fractured vertebral body angle, ${ }^{\circ}$} \\
\hline - Wang et al [5] & $6.6 \pm 4.0$ & $7.9 \pm 4.9$ & .396 \\
\hline - Wild et al [4] & 7.7 & 12.2 & \\
\hline \multicolumn{4}{|c|}{ Anterior vertebral body height, $\%$} \\
\hline - Wang et al [5] & $21.0 \pm 11.8$ & $28.6 \pm 18.7$ & .155 \\
\hline \multicolumn{4}{|c|}{ Posterior vertebral body height, $\%$} \\
\hline -Wang et al [5] & $4.4 \pm 3.2$ & $6.2 \pm 4.8$ & .196 \\
\hline \multicolumn{4}{|c|}{ Bisegmental wedge angle, ${ }^{\circ}$} \\
\hline - Wild et al [4] & 2.6 & 2.4 & \\
\hline \multicolumn{4}{|l|}{ Clinical } \\
\hline \multicolumn{4}{|c|}{ VAS (incisional pain) } \\
\hline - Wang et al [5] & $1.5 \pm 0.9$ & $2.2 \pm 0.8$ & $<.05$ \\
\hline \multicolumn{4}{|l|}{ MacNab criteria } \\
\hline - Wang et al [5] & 88.2 & 85.7 & \\
\hline \multicolumn{4}{|c|}{ Hannover spine score } \\
\hline - Wild et al [4] & 84.8 & 78 & \\
\hline \multicolumn{4}{|l|}{ SF-36 } \\
\hline - Wild et al [4] & 59.1 & 50 & .069 \\
\hline
\end{tabular}

\begin{tabular}{|c|c|c|c|}
\hline Outcome & $\begin{array}{l}\text { Minimally } \\
\text { invasive }\end{array}$ & Open & $\boldsymbol{P}$ \\
\hline Perioperative & Mean \pm SD & Mean \pm SD & \\
\hline \multicolumn{4}{|c|}{ Surgical blood loss, mL } \\
\hline - Wang et al [5] & $83.5 \pm 51.8$ & $304.8 \pm 209.1$ & .000 \\
\hline - Wild et al [4] & $194.4 \pm 72.6$ & $380 \pm 198.9$ & .017 \\
\hline \multicolumn{4}{|c|}{ Postoperative blood loss, mL } \\
\hline - Wang et al [5] & $14.4 \pm 4.3$ & $350.1 \pm 204.5$ & .000 \\
\hline - Wild et al [4] & $155.6 \pm 35.0$ & $441.1 \pm 162.3$ & .000 \\
\hline \multicolumn{4}{|c|}{ Operation time, min } \\
\hline - Wang et al [5] & $97.1 \pm 15.3$ & $161.0 \pm 72.5$ & \\
\hline - Wild et al [4] & 87.4 & 80.9 & \\
\hline \multicolumn{4}{|l|}{ Hospital stay, days } \\
\hline - Wang et al [5] & $11.1 \pm 3.8$ & $22.9 \pm 14.1$ & \\
\hline Complications & $\%$ & $\%$ & \\
\hline \multicolumn{4}{|l|}{ Screw malposition } \\
\hline - Wang et al [5] & 0.0 & 2.1 & \\
\hline - Wild et al [4] & 0.0 & 0.0 & \\
\hline \multicolumn{4}{|l|}{ Infection } \\
\hline - Wild et al [4] & 0.0 & 0.0 & \\
\hline \multicolumn{4}{|c|}{ Neurological symptoms } \\
\hline - Wild et al [4] & 0.0 & 0.0 & \\
\hline \multicolumn{4}{|l|}{ Incisional stagger } \\
\hline - Wild et al [4] & 0.0 & 11.8 & \\
\hline \multicolumn{4}{|c|}{ Deep vein thrombosis } \\
\hline - Wild et al [4] & 0.0 & 5.9 & \\
\hline
\end{tabular}

* From preoperative to postoperative. 


\section{DISCUSSION}

\section{- Limitations include:}

- Small number of poor studies available (two studies, both level III).

- Limited emphasis on patient-reported outcomes.

- Percutaneous MIS can provide a safe and effective treatment for thoracolumbar junction fractures (Table 4).

- A significant reduction in blood loss, postoperative pain, surgical time, and hospital stay are the main advantages associated with these new minimally invasive techniques.

- These favorable outcomes are particularly important in specific subgroups of patients, including elderly people and patients with important comorbidities, and could make the percutaneous minimally invasive techniques the preferable surgical treatment.

- However, long-term maintenance of sagittal profile's correction and difficulty in reconstructing the anterior column via a posterior approach only remain an important element to consider.

- Among potential disadvantages of percutaneous techniques, spinal fusion has to be considered. While fusion is more feasible in open surgical procedures, it is difficult to achieve with minimally invasive techniques.

- More studies with a longer follow-up, including randomized trials, are necessary to evaluate the theoretical benefit of percutaneous techniques and to assess whether the results of the latters are as durable as the ones achieved by open surgery.

\section{ILLUSTRATIVE CASE}

A 67-year-old woman presented with a 3-month history of severe pain in the dorsal and lumbar regions of her spine. Symptoms made her ambulation difficult, as well as sitting and sleeping.

Her medical history was remarkable for myocardial infarction; insulin-dependent diabetes; HCV-related hepatitis; and diabetes-related retinopathy and neuropathy. She reported to have undergone, in 2010, a vertebroplasty for a fracture of Th12 (Fig 2). Postoperatively, she improved considerably and remained well until October 2011 , when a new spinal trauma caused a type B 1.2 fracture of the same vertebra associated with a fracture of the anteroinferior portion of the 11 th posterior vertebra and a minor lesion of the posterosuperior end plate of L1 (Fig 3).

The patient was consented for a Th10-Th1 1-L1-L2 percutaneous pedicle screw fixation. Following this procedure, a satisfactory spinal stability and alignment was obtained as well as improvement of the 12th vertebral body's height (Fig 4). At 1-year follow-up, the patient remains unchanged (Fig 5).
Fig 2 Lateral thoracolumbar $x$-ray showing a vertebroplasty of Th12.

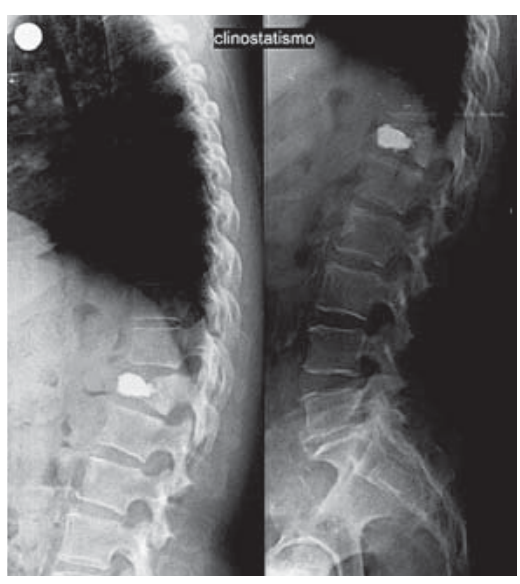

Fig 3a Lateral thoracolumbar $x$-ray showing the recurrent posttraumatic fracture of Th1 2 as well as the fracture of the anteroinferior surface of the Th1 1 vertebral body. An obvious kyphosis at the same levels is also seen.

b Sagittal reformatted CT image revealing the Th11 and Th12 vertebral bodies' fractures. Also perceived is a signal change in the posterosuperior area of the $\mathrm{L} 1$ vertebra.

c Sagittal T2-weighted MR image confirming the Th1 1 and Th12 fractures. A signal change in keeping with an impact fracture of the posterosuperior bone of the L1 vertebra is also seen.
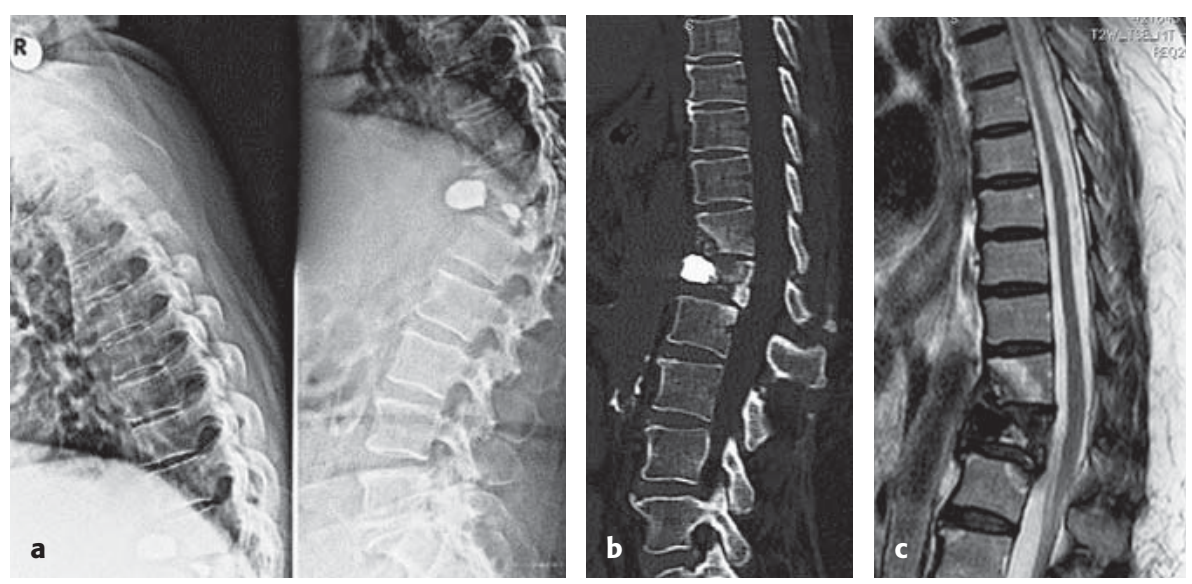
Fig 4 Postoperative lateral thoracolumbar $\mathrm{x}$-ray showing the reduced kyphosis and correct sagittal alignment following the percutaneous Th10-Th11-L1-L2 fixation.

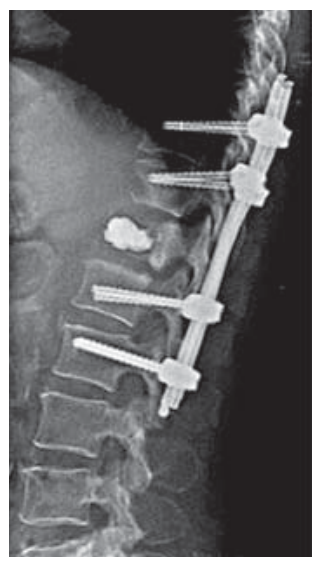

Fig 5 AP (a) and sagittal (b) thoracolumbar, 1-year follow-up $x$-ray confirming the acquired stability of the thoracolumbar junction, with marked reduction of the focal kyphosis.

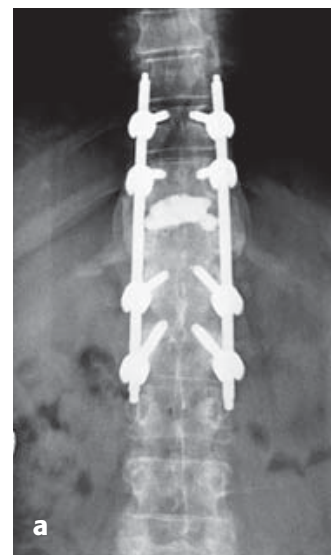

Table 4 Rating of overall strength of evidence for each key question.*

\begin{tabular}{|c|c|c|c|c|c|c|c|c|}
\hline \multicolumn{9}{|c|}{$\begin{array}{l}\text { Question 1: What is the comparative effectiveness of percutaneous minimally invasive versus open spine surgery } \\
\text { for thoracolumbar fractures? }\end{array}$} \\
\hline Outcome & \multicolumn{4}{|c|}{ Strength of evidence } & Conclusions/comments & Baseline & Downgrade & Upgrade \\
\hline Radiographic & Very low & Low & Moderate & $\int^{\text {High }}$ & $\begin{array}{l}\text { Radiographic outcomes that include } \\
\text { sagittal angle, fractured vertebral body } \\
\text { angle, anterior and posterior vertebral } \\
\text { body height, and bisegmental wedge } \\
\text { angle were similar between } \\
\text { percutaneous minimally invasive and } \\
\text { open surgery }\end{array}$ & Low & Imprecision (1) & No \\
\hline Clinical & \multicolumn{2}{|l|}{ Very low } & Moderate & ${ }^{\text {High }}$ & $\begin{array}{l}\text { Postoperative incisional pain was less } \\
\text { following percutaneous minimally } \\
\text { invasive surgery (MIS) } \\
\text { Patient-reported and clinician-based } \\
\text { outcomes were similar at follow-up } \\
\text { between groups }\end{array}$ & Low & Single study (1) & No \\
\hline \multicolumn{9}{|c|}{$\begin{array}{l}\text { Question 2: What is the comparative safety of percutaneous minimally invasive versus open spine surgery } \\
\text { for thoracolumbar fractures? }\end{array}$} \\
\hline Outcome & & & & & Conclusions/comments & Baseline & Downgrade & Upgrade \\
\hline Perioperative & Very low & Low & Moderate & $\stackrel{\text { High }}{\text { High }}$ & $\begin{array}{l}\text { Blood loss at surgery and in the } \\
\text { postoperative period was less with } \\
\text { percutaneous MIS compared with open }\end{array}$ & Low & No & No \\
\hline Complications & Very low & Low & Moderate & High & $\begin{array}{l}\text { There were no complications reported } \\
\text { for percutaneous MIS in two small } \\
\text { studies }\end{array}$ & Low & No & No \\
\hline
\end{tabular}

* Baseline quality: High indicates majority of article Level I/II; low, majority of articles Level III/IV. Upgrade: Large magnitude of effect (1 or 2 levels); dose response gradient (1 level).

Downgrade: Inconsistency of results (1 or 2 levels); indirectness of evidence (1 or 2 levels); imprecision of effect estimates (1 or 2 levels). 


\section{REFERENCES}

1. Hu R, Mustard CA, Burns C (1996) Epidemiology of incident spinal fracture in a complete population. Spine (Phila Pa 1976); 21(4):492499.

2. Jansson KA, Blomqvist $P$, Svedmark $P$, et al (2010) Thoracolumbar vertebral fractures in Sweden: an analysis of 13,496 patients admitted to hospital. Eur J Epidemiol; 25(6):431437.

3. Ostelo RW, de Vet HC (2005) Clinically important outcomes in low back pain. Best Pract Res Clin Rheumatol; 19(4):593-607.

4. Wild MH, Glees $M$, Plieschnegger $C$, et al (2007) Five-year follow-up examination after purely minimally invasive posterior stabilization of thoracolumbar fractures: a comparison of minimally invasive percutaneously and conventionally open treated patients. Arch Orthop Trauma Surg; 127(5):335-343.

5. Wang HW, Li CQ, Zhou Y, et al (2010) Percutaneous pedicle screw fixation through the pedicle of fractured vertebra in the treatment of type A thoracolumbar fractures using Sextant system: an analysis of 38 cases. Chin J Traumatol; 13(3):137-145.

\section{EDITORIAL PERSPECTIVE}

Our reviewers congratulate Barbagallo and colleagues for their work. The subject of minimally invasive spine surgery (MIS) has provided a steady stream of new investigation opportunities - this topic of thoracolumbar trauma fixation is certainly an interesting one. However, MIS has become more invasive over time while traditional open surgery has become more soft-tissue aware-in a way less invasive. The two entities are somehow engaged in a form of approximation process.

The statements below are more a reflection of the methodological shortcomings of the literature per se rather than the quality of the work of the authors or the technologies available-MIS versus open.

In summary, there is a surprising paucity of scientifically highgrade studies on this topic of a new technology, which should have ideally been introduced with comparison studies from the start, preferably with randomization. Instead we are left with case series and another new technology trying to achieve credibility based on CoE Level III or IV.

The current data certainly suffices to establish that there is therapeutic equipoise, thus setting the stage for a future comparison trial.
To summarize, some of the recurrent shortcomings of the literature to date are:

- Lack of a validated injury severity score in rating injury types and severity. It can be safely assumed by now that the venerable AO system does not adequately differentiate injury severity and has limitations in inter-observer reliability. A3 in Basel, Switzerland $\neq A 3$ in Los Angeles, $C A$, etc.

- Kyphosis angles: These are interesting points but not really important as they largely lack correlation to patient outcomes, which we actually know by now. Hardware loosening, bending, radiolucency are probably more significant to determine bone healing, but here the variables are overwhelming. Bone graft type, technique, and host climate as well as surgical technique (accuracy in screw placement on first try, caliber of implants relative to bony anatomy, osteopenia) are all relevant variables and create a challenge to any study design.

- Patient-reported outcomes: There is an ever-growing number of patient-related outcomes tests, sadly mostly without the prerequisite validation studies. No need to collect data for another cute homegrown questionnaire. Stay with simple but validated tests to get the big picture and think how you can express functional recovery of the patient. Certainly, the statement that incisional pain was significantly less in the MIS group (1.5 versus 2.2) should be followed-up with a statement of what generally constitutes minimally important clinical differences for the VAS scale. A difference of 0.7 on VAS is NOT clinically significant.

- Length of follow-up and reoperation rates: Follow-up of 1 year is a start but not more than that. Two years for patients with possible incomplete fusions sounds more meaningful.

- Cost burden: This is a vast topic and unpredictable in terms of its eventual findings. Newer technologies are in general substantially more resource intensive, requiring advanced imaging systems and biological graft supplements in addition to being substantially more expensive on a device basis compared with traditional systems. Radiation exposure to patients and staff, operating room times, and learning curves are other factors. Counterbalance that with reduced infection rates, less blood loss, and a possibly more rapid return to function may be important counterarguments. The immediate cost burden to society is not known, and differs from country to country due to the circuitous routes of healthcare reimbursement.

Undoubtedly this topic of MIS versus open treatment for TL spine fractures is rife for a larger scale multicenter evaluationit will take comprehensive and large-scale patient enrollment from dedicated investigators over multiple years to find an answer. The authors of this article certainly have provided the basis for a further more formal investigation. Who will rise to the challenge? 